\title{
The Straightforward Route Towards the Theoretical Specific Free Enthalpy of Electrochemical Reactions
}

Roland H. Pawelke

\begin{abstract}
This paper outlines a simple yet precise method for identifying the theoretical specific free enthalpy of electrochemical reactions on basis of the ideal gas law, equilibrium thermodynamics and Faraday's law, exploiting the normative role of the standard hydrogen electrode in electrochemistry. The result of this approach are discussed in relation to four battery cell reaction examples: $\mathrm{LiCoO}_{2} / \mathrm{C}_{6}$, $\mathrm{LiFePO}_{4} / \mathrm{C}_{6}$, sodium-sulfur (NAS) and $\mathrm{NaCl}-\mathrm{Ni}$ (ZEBRA). The agreement between calculated and practical values is near-excellent for even stoichiometries which bespeaks the virtually ideal nature of reversible reactions and the quality of the practical optimization efforts alike. These findings highlight the principal nature of intrinsic thermodynamic limitation to equilibrium mass transfer and its key role towards understanding reversible chemical energy storage in a global sense.
\end{abstract}

\section{Introduction}

The ideal gas law is a cornerstone to the conception of natural science and the structure of classic physical chemistry is essentially built on a fundament comprising of the ideal gas law and equilibrium thermodynamics which e.g. shows in the thermodynamic standard state at 1 unit of pressure (and not for example 1013.25 units) or the normative role of the standard hydrogen electrode (SHE) in electrochemistry. A matter of little, if any, recognition is that the ideal gas law provides a means for marking out the intrinsic thermodynamic boundaries to reversible hydrogen mass transfer in equilibrium systems: ${ }^{1}$ the reversible transfer of $1 \% \mathrm{w} / \mathrm{w}$ $\mathrm{H}$ by sum formula from a sorbent into the gas phase relates in the ideal hydrogen case to the chemical potential of $-12033 \mathrm{~J}\left(\mathrm{~mol} \mathrm{H}_{2}\right)^{-1}$ and any ideal hydrogen transfer scales proportionally to the chemical potential gradient between gas and sorbent phase by the mass transfer constant $\mu_{1 \%}{ }^{\circ}=-12033 \mathrm{~J}\left(\mathrm{~mol} \mathrm{H}_{2}\right)^{-1}[1 \% \mathrm{w} / \mathrm{w} \mathrm{H}]^{-1}$.

This is derived for hydrogen storage in reversible metal hydrides. Yet due to the universality of thermodynamics, the equilibrium approach's indifference towards the hydrogen sorbent and the normative role of the standard hydrogen electrode (SHE), the principle of intrinsic thermodynamic constraint to mass transfer must be recognizable in electrochemistry, too. Hence it is worthwhile to investigate for how this principle may be worked out and what its relation to practice is like.

\section{Methodical Approach}

By the ideal gas law, the transfer of $1 \% \mathrm{w} / \mathrm{w} \mathrm{H}$ from a sorbent into the gas phase is linked to the chemical potential $\mu_{1 \%}{ }^{\circ}=-12033 \mathrm{~J}\left(\mathrm{~mol} \mathrm{H}_{2}\right)^{-1}$. ${ }^{1}$ For the chemical potential equals molar free enthalpy, this may be translated by Faraday's law $\Delta G^{\circ}=-z \mathrm{~F} E^{\circ}$ to an according standard hydrogen potential $\mathrm{E}_{1 \% \mathrm{H}^{\circ}}: z$ is the charge-mol equivalent of the reaction, thus $z_{\mathrm{H} 2}=2 \mathrm{~mol}$, and $\mathrm{F}$ is the Faraday constant of $96485.3329 \mathrm{C} \mathrm{mol}^{-1}$; the calculation is shown in equation 1.

$\mu_{1 \%}{ }^{\circ}=-12033 \mathrm{~J}\left(\mathrm{~mol} \mathrm{H}_{2}\right)^{-1}[1 \% \mathrm{w} / \mathrm{w} \mathrm{H}]^{-1}=\Delta G_{\mathrm{m}}{ }^{\circ}=-z \mathrm{FE}_{1 \% \mathrm{H}^{\circ}}$

$E_{1 \% H^{\circ}}=0.06236 \mathrm{~V}[1 \% \mathrm{w} / \mathrm{w} \mathrm{H}]^{-1}$ 
That the division of a chemical gas potential $\mu_{\mathrm{H} 2}$ by $\mu_{1 \% \mathrm{H}}$, both logarithmic quantities, indeed results in direct proportionality is demonstrably true: ${ }^{1}$ consequently, dividing a SHE potential $E^{\circ}$ by $\mathrm{E}_{1 \% \mathrm{H}^{\circ}}$ yields an according $[ \pm \Delta \% \mathrm{w} / \mathrm{w} \mathrm{H}$ ] as equation 2 shows. That is because Faraday's law may be seen the pendant to the ideal gas law in terms charge and electrical potential, the equivalency of chemical to electrical potential applies for hydrogen is a neutral species. ${ }^{2}$

$\frac{E^{\circ}}{\mathrm{E}_{1 \% \mathrm{H}^{\circ}}}=[ \pm \Delta \% \mathrm{w} / \mathrm{w} \mathrm{H}]$

By means of equation 2, the SHE potential excursion featured by the other half-cell can be translated to a hydrogen mass transfer amount in $\% \mathrm{w} / \mathrm{w} \mathrm{H}$ : The arithmetic sign convention reflects the sorbent-phase centred model by which $\mu_{1 \% H}{ }^{\circ}$ is defined: ${ }^{1}$ a negative $E^{\circ}$ potential indicates a negative hydrogen mass transfer with regard to the SHE sorbent $(\mathrm{HCl})$, thus towards the gas phase, in line with the common SHE convention. That relative hydrogen mass amount can be alternately expressed by means of a quotient of absolute masses as shown in equation $3 \mathrm{a}$, respective mol number as shown in equation $3 \mathrm{~b}$.

$[ \pm \Delta \% \mathrm{w} / \mathrm{w} \mathrm{H}]=\frac{\Delta m_{\mathrm{H} 2}[\mathrm{~g}]}{100 \mathrm{~g}}$

$\frac{\Delta m_{\mathrm{H} 2}[\mathrm{~g}]}{M_{\mathrm{H} 2} 100 \mathrm{~g}}=\frac{\Delta n_{\mathrm{H} 2}}{100 \mathrm{~g}}$

In relation to the half cell reaction featuring the potential excursion $E^{\circ}$, the information about specific hydrogen mol number translates to a corresponding mass amount of the migrating ionic species $X$ via the charge-mol equivalents $z_{\mathrm{X}}$ respective $z_{\mathrm{H} 2}=2$ and the molar mass $M_{X}$, as equation 4 shows.

$\frac{\Delta n_{\mathrm{H} 2}}{100 \mathrm{~g}} \frac{z_{X} M_{X}}{2}=\frac{\Delta m_{X}}{100 \mathrm{~g}}$

The equivalent-mass change $\Delta m_{X}$ is expressed in terms of mol number $\Delta n_{X}$ by dividing it by $M_{x}$ which partly reverses (illustrative) equation 4 . The expression for the equivalent-mol number $\Delta n_{x}$ to hydrogen on basis of equations $3 \mathrm{~b}$ and 4 thus simplifies as equation 5 shows.

$\frac{\Delta m_{X}}{100 \mathrm{~g}} \frac{1}{M_{X}}=\frac{\Delta n_{X}}{100 \mathrm{~g}}=\frac{\Delta n_{\mathrm{H} 2}}{100 \mathrm{~g}} \frac{z_{X}}{2}$

Equation 5 conveys under the premise of ideal equilibrium how many mol of species $X$ can be transferred until the featured SHE potential gradient $E^{\circ}$ is dissipated: this depends only on charge respective redox equivalents. Equation 6 shows the subsuming of all transformations since equation 2 with $E^{\circ}$ now being indexed as $E_{X}^{\circ}$ in accordance with the above reasoning. 
$\frac{E_{X}^{\circ}}{E_{1 \% \mathrm{H}}^{\circ}} \frac{z_{X} M_{x}}{2 M_{\mathrm{H} 2}} \frac{1}{A_{*}}\left[\mathrm{~mol} \mathrm{~g}^{-1}\right]=\frac{\Delta n_{X}}{100 \mathrm{~g}}\left[\mathrm{~mol} \mathrm{~g}^{-1}\right]$

Equation 6 can be further simplified if $\left(2 M_{\mathrm{H}_{2}}\right)$ is set to a constant of $4 \mathrm{~g}$ (mol) $)^{-1}$ and a factor 10 is introduced for scaling to the more common $\mathrm{kg}$ mass reference as equation 7 shows.

$\frac{\Delta n_{X}}{100 \mathrm{~g}}\left[\mathrm{~mol} \mathrm{~g}^{-1}\right]=10 \frac{E_{X}^{\circ}}{\mathrm{E}_{1 \% \mathrm{H}^{\circ}}} \frac{z_{X}}{4}\left[\mathrm{~mol} \mathrm{~g}^{-1}\right]$

The specific mass transfer in mol of species $X$ is converted by means of Faraday's law into the corresponding specific Gibbs standard enthalpy $\Delta G_{s}^{\circ}$ on a charge-mol equivalent basis: equation 8a shows the accordingly transformed expression for $\Delta G_{s}^{\circ}$ while equation $8 \mathrm{~b}$ is its pendant for the common unit of $\mathrm{Wh} \mathrm{kg}^{-1}$.

$\frac{\Delta G^{\circ}}{1000}\left[\mathrm{~J} \mathrm{~g}^{-1}\right]=-\frac{\left(E_{X}^{\circ} \cdot Z_{X}\right)^{2}}{E_{1 \% \mathrm{H}}{ }^{\circ}} \frac{10 \mathrm{~F}}{4}\left[\mathrm{~J} \mathrm{~g}^{-1}\right]$

$\Delta G_{s}^{\circ}\left[\mathrm{Wh} \mathrm{kg}^{-1}\right]=-\frac{\left(E_{X}^{\circ} \cdot z_{X}\right)^{2}}{E_{1 \% \mathrm{H}^{\circ}}} \frac{10 \mathrm{~F}}{4 \cdot 3600}\left[\mathrm{Wh} \mathrm{kg}^{-1}\right]$

Equation $8 \mathrm{~b}$ is an important intermediate result and it is noteworthy that always a negative $\Delta G_{s}{ }^{\circ}$ is obtained regardless of the arithmetic sign of $E_{X}{ }^{\circ}$ as it must because spontaneous mass transfer at the SHE electrode occurs in both cases. It is subsequently investigated how the fundamental regularity of equation $8 \mathrm{~b}$ relates further to practice.

\section{Results}

Equation $8 b$ is applied to the well-known SHE potentials of the redox pairs $\mathrm{Li} / \mathrm{Li}^{+}$and $\mathrm{Na} / \mathrm{Na}^{+},{ }^{3}$ shown in equations $9 a$ and $9 b$, respectively.

$\begin{array}{llll}\mathrm{Li} / \mathrm{Li}^{+} & E_{\left(\mathrm{L} / \mathrm{Li}^{+}\right)}{ }^{\circ}=-3.040 \mathrm{~V} & \Rightarrow & \Delta G_{\mathrm{s}}{ }^{\circ}=-9929.9 \mathrm{Wh} \mathrm{kg}^{-1} \\ \mathrm{Na} / \mathrm{Na}^{+} & E_{\left(\mathrm{Na} / \mathrm{Na}^{+}\right)^{\circ}}=-2.713 \mathrm{~V} & \Rightarrow & \Delta G_{\mathrm{s}}{ }^{\circ}=-7908.5 \mathrm{Wh} \mathrm{kg}^{-1}\end{array}$

These specific free enthalpy (energy if bottled up) values refer to the redox transition of a $\mathrm{kg}$ of the respective bare metal: yet their actual proportion in terms of mass is only a fraction of respective battery cell reactions. Thus, application of equation $8 b$ respective $9 a$ or $9 b$ values to a distinct reaction formula requires their adjustment to the respective mass proportion. This yields the specific enthalpy if the SHE potential gradient of $E_{X}{ }^{\circ}$ is $100 \%$ dissipated by mass transfer i.e. a complete discharge; equation 10 shows that accordingly.

$\Delta G_{s}^{\circ}\left[\mathrm{Wh} \mathrm{kg}^{-1}\right]=-\frac{\left(E_{X}^{\circ} \cdot z_{X}\right)^{2}}{E_{1 \% H^{\circ}}} \frac{10 \mathrm{~F}}{4 \cdot 3600} \frac{m_{X}}{m_{\text {reaction }}}\left[\mathrm{Wh} \mathrm{kg}^{-1}\right]$ 
Yet terms and conditions apply to practical electrochemical reversibility; a factor suiting the purist approach while sparing the need for any discussion of deeper causes is the discharge voltages quotient $x=\left(U_{\text {start,dc }}-U_{\text {cut-off,dc }}\right) / U_{\text {output }}$ : this factor captures to what extent the base voltage gradient of $E_{X}{ }^{\circ}$ is dissipated but expressed in actual battery cell voltage terms. This applies with general validity and in proportion due to the normative role of SHE potentials respective Faraday's law; equation 11 shows the accordingly amendments.

$\Delta G_{s}^{\circ}\left[\mathrm{Wh} \mathrm{kg}^{-1}\right]=-\frac{\left(E_{X}{ }^{\circ} \cdot z_{X}\right)^{2}}{E_{1 \% \mathrm{H}}{ }^{\circ}} \frac{10 \mathrm{~F}}{4 \cdot 3600} \frac{m_{X}}{m_{\text {reaction }}} \quad\left[\mathrm{Wh} \mathrm{kg}^{-1}\right]$

The three cell voltages are usually readily available information, e.g. in practice attainable from the data sheet of a commercial battery cell.

Equation 12 shows a prominent secondary Li-battery reaction, comprising of a $\mathrm{LiCO}_{2}$ cathode and a graphite anode: this example is considered on basis of the data for the commercial Panasonic NCR18650B (3.35 Ah) cell with $U_{\text {start,dc }}=4.2 \mathrm{~V}, U_{\text {cut-off, dc }}=2.5 \mathrm{~V}$ at $U_{\text {output }}=3.6 \mathrm{~V}$, resulting in a factor $x=0.472$ in equation 12 This is for determining the graphite amount as affecting the gravimetric proportion of lithium which figures at $x=0.472$ to [5.262 \% w/w Li].

$\mathrm{LiCoO}_{2}+x \mathrm{C}_{6} \rightleftharpoons \mathrm{Li}_{(1-x)} \mathrm{CoO}_{2}+x \mathrm{LiC}_{6}$

$-9929.9 \mathrm{Wh} \mathrm{kg}^{-1} \cdot 0.05262 \cdot \frac{4.2 \mathrm{~V}-2.5 \mathrm{~V}}{3.6 \mathrm{~V}}=-247 \mathrm{Wh} \mathrm{kg}^{-1}$

The battery cell datasheet gives for the reaction at bare cell dimensions a specific energy value of $243 \mathrm{Wh} \mathrm{kg}^{-1}$, in excellent agreement to the calculated value.

Another well-known lithium secondary battery chemistry utilizes $\mathrm{LiFePO}_{4}$ as cathode which is shown in equation 13 in combination with a graphite anode: this example is considered on basis of the data for the commercial AA Portable Power Corp LFP18650-1500 (1.40 Ah) secondary battery cell with $U_{\text {start,dc }}=3.65 \mathrm{~V}, U_{\text {cut-off, dc }}=2.5 \mathrm{~V}$ at $U_{\text {output }}=3.2 \mathrm{~V}$, resulting in a factor of $x=0.359$ in equation 13. Hence this corresponds to a gravimetric proportion of $[3.780 \% \mathrm{w} / \mathrm{w} \mathrm{Li}]$ in the sum formula of equation 12.

$\mathrm{LiFe}^{\prime \prime} \mathrm{PO}_{4}+x \mathrm{C}_{6} \rightleftharpoons \mathrm{Li}_{(1-x)} \mathrm{Fe}^{\prime \prime \prime} \mathrm{PO}_{4}+x \mathrm{LiC}_{6}$

$-9929.9 \mathrm{Wh} \mathrm{kg}^{-1} \cdot 0.03780 \cdot \frac{3.65 \mathrm{~V}-2.5 \mathrm{~V}}{3.2 \mathrm{~V}}=-135 \mathrm{Wh} \mathrm{kg}^{-1}$

The specific energy of the LFP18650-1500 cell at the nominal capacity of 1.4 Ah figures to 109 $\mathrm{Wh} \mathrm{kg}$ and at the maximum capacity of $1.5 \mathrm{Ah}$, it is $117 \mathrm{Wh} \mathrm{kg}^{-1}$, on basis of the mass of the encased cell of $41 \mathrm{~g}$. Therefore, the result of equation 13 can be considered in very good agreement, all the more it does not account for any facultative reactant ratio variation.

The sodium-sulfur (NAS) battery reaction is rather complex due to its multiple polysulphide intermediates: ${ }^{4,5} 100 \%$ depth-of-discharge (DOD) is not defined by reduction of the sulfur electrolyte to $\mathrm{Na}_{2} \mathrm{~S}$ but $\mathrm{Na}_{2} \mathrm{~S}_{3}{ }^{6}$ Yet in practice, the NAS battery cell is often designed to stop 
discharging at 85 to $90 \%$ of that theoretical capacity due to the corrosive nature of $\mathrm{Na}_{2} \mathrm{~S}_{3}{ }^{7}$ The NAS battery shows a stable open circuit voltage (OCV) of $2.075 \mathrm{~V}$ up to $59 \%$ DOD, just short of the stoichiometry $\mathrm{Na}_{2} \mathrm{~S}_{5}$ at 60\% DOD. Then the OCV drops rather linearly to $1.78 \mathrm{~V}$ at the stoichiometry $\mathrm{Na}_{2} \mathrm{~S}_{3}$ respective $100 \%$ DOD. ${ }^{4,8}$ In $\mathrm{Na}_{2} \mathrm{~S}_{5}$ amounts the sodium mass proportion to [22.287\% w/w Na], in $\mathrm{Na}_{2} \mathrm{~S}_{3}$ it is [32.340\% w/w Na] accordingly; adjusting to the 60:40 DOD ratio, the sodium mass percentage of the reaction(s) shown in equation 14 is thus $[26.3082 \% \mathrm{w} / \mathrm{w} \mathrm{Na}]$, with $U_{\text {start,dc }}=2.075 \mathrm{~V}, U_{\text {cut-off, dc }}=1.78 \mathrm{~V}$ and $U_{\text {output }}=2.075 \mathrm{~V}$.

$2 \mathrm{Na}+0.625 \mathrm{~S}_{8} \rightleftharpoons \mathrm{Na}_{2} \mathrm{~S}_{5}(60 \% \mathrm{DOD})$

$\mathrm{Na}_{2} \mathrm{~S}_{5}+2 \mathrm{Na}+0.125 \mathrm{~S}_{8} \rightleftharpoons 2 \mathrm{Na}_{2} \mathrm{~S}_{3}(100 \% \mathrm{DOD})$

$-7908.5 \mathrm{Wh} \mathrm{kg}^{-1} \cdot 0.263082 \cdot \frac{2.075 \mathrm{~V}-1.780 \mathrm{~V}}{2.075 \mathrm{~V}}=-296 \mathrm{Wh} \mathrm{kg}^{-1}$

The NGK insulators NAS-cell T5 model represents the alleged pinnacle of this technology; it features a rated voltage of $2.075 \mathrm{~V}$ and a rated capacity of $632 \mathrm{Ah}$ at a reactant mass of 5.5 kg. ${ }^{4,9}$ These figures yield a nominal specific energy of $238 \mathrm{Wh} \mathrm{kg}^{-1}$; however, the T5 cells are designed to give that value in practice after 2500 cycles and at $81 \%$ DC efficiency. ${ }^{10}$ Thus, the specific energy at theoretical $100 \%$ DC efficiency is $294 \mathrm{Wh} \mathrm{kg}^{-1}$.

The reaction of the ZEBRA-battery in the classic $\mathrm{NaCl}-\mathrm{Ni}$ setup is in its essence shown in equation 15: it features an open circuit voltage (OCV) of $2.58 \mathrm{~V}$, the operational window for 0 to $100 \%$ state of charge (SOC) lies between $1.58 \mathrm{~V}$ and $2.58 \mathrm{~V} .{ }^{11}$ Beyond a SOC of $98 \%$, there is an overcharge reaction which raises the OCV up to $3.05 \mathrm{~V} .^{4,11}$ The sodium mass proportion in $(\mathrm{NaCl})_{2}-\mathrm{Ni}$ amounts to [26.187\% w/w Na]: equation 15 shows the according calculation with $U_{\text {start, dc }}=2.58 \mathrm{~V}, U_{\text {cut }- \text { off }, \text { dc }}=1.58 \mathrm{~V}$ and $U_{\text {output }}=2.58 \mathrm{~V}$.

$\mathrm{Ni}+2 \mathrm{NaCl} \rightleftharpoons \mathrm{NiCl}_{2}+2 \mathrm{Na}$

$-7908.5 \mathrm{Wh} \mathrm{kg}^{-1} \cdot 0.26187 \cdot \frac{2.58 \mathrm{~V}-1.58 \mathrm{~V}}{2.58 \mathrm{~V}}=-803 \mathrm{Wh} \mathrm{kg}^{-1}$

The result of $803 \mathrm{Wh} \mathrm{kg}^{-1}$ is adjusted to the $98 \%$ SOC limit due to the overcharge reaction, ${ }^{4,11}$ which yields $787 \mathrm{Wh} \mathrm{kg}^{-1}$, concisely the theoretical value of LI et al $\left(305 \mathrm{Ah} \mathrm{kg}^{-1}\right.$ at $\left.2.58 \mathrm{~V}\right){ }^{12}$

\section{Discussion}

The specific free enthalpy respective energy of even a multi-step electrochemical reaction as seen for the NAS-battery can be determined with fine precision by means of the outlined approach. From its foundations towards its result, the line of argument is tight; hence there is not really much need for a discussion of the event as such. The founding principle of intrinsic thermodynamic limitation to reversible hydrogen mass transfer may be challenged but can be easily accounted for: ${ }^{1}$ the only point meriting special attention is that the division of an ideal gas chemical potential by a calibration standard of the kind, both logarithmic quantities, results in linear proportionality. That builds the bridge to Faraday's law and from there it's all linear relations down the road. 
Reversibility as a thermodynamic concept essentially presupposes ideal behaviour and the insights gained from that are insofar fundamental and definite as figuring the as-good-as-itgets. This work is not concerned with the deeper causes why in practice reversibility of an electrochemical cell reaction is usually confined to merely a fraction of the potential gradient but the form of equation 11 suggests it being the baseline for any consideration of the kind. As such, it is not really a surprise that this ideal general thermodynamic approach applies very well to the subject of reversible chemical energy storage, in contrast to the seemingly matter of fact that its first time outline took until the early $21^{\text {st }}$ century.

Nevertheless, the closeness of practical specific energy values to those obtained by ideal theory is quite astonishing and may be seen an impressive testimony of skilled engineering dedicated to particular purpose. In contrast, this paper presents a simple yet powerful tool wielding which does neither require a high degree of specialization nor even an actual vested interest in the art. Irrespective of the reaction that may evoke, objectively it allows the quick and concise assessment of battery specific energy claims with general validity by means of a few, usually readily available, parameters.

It is from a classic scientific perspective satisfying that reversible energy storage is ultimately all about the fundamental concepts of (physical) chemistry: the ideal gas law, equilibrium thermodynamics, Faraday's law, particle-equivalents in terms of various qualities etc. It also substantiates the understanding of chemistry being an art in its own right, not some auxiliary skill to engineering, physics or medicine pursuits seeking to manipulate matter for particular ends. In conclusion, this is an instructive demonstration for the importance and ultimate advantage of seeking a classic global understanding of a scientific subject somewhat independent of an interest in particular ends: emphasizing the latter over the former may lead eventually to the same result in a specific case but likely at the price of disproportionate effort due to the impoverishment in global meaning and metrics. Thus, it is consequential up to compelling for the end-focused positivist mindset to either deny the existence or belittle the role of both: This paper has the privilege of making that one point about the profound difference in quality of insight and required effort, if positivist utilitarian expediency, which is ultimately a non-expediency, is forfeited as the final philosophy of science. ${ }^{13}$

\section{Conclusions}

The theoretical specific energy of electrochemical reactions can be precisely determined by an approach combining the ideal gas law, equilibrium thermodynamics and Faraday's law with special regard to intrinsic thermodynamic limitation to reversible mass transfer, exploiting the normative role of SHE potentials to electrochemistry. This is possible because of the essentially ideal nature of reversible reactions; it is noteworthy though that understanding the matter globally from a classic principles vantage point, not one of particular interest, unveiled this simple yet powerful tool of practical value, open to virtually everyone.

\section{Acknowledgements}

This article originates from work done at FOTEC Forschungs- und Technologietransfer GmbH in Wiener Neustadt, Austria, under grants $4000105330 / 12 /$ NL/CLP by the European Space Agency and A-1341-RT-GP by the European Defence Agency, which is all gratefully acknowledged. 


\section{Conflicts of interest}

There are no conflicts to declare.

\section{References}

1 R. H. Pawelke, The Master Key to the Problem of Reversible Chemical Hydrogen Storage is $12 \mathrm{~kJ}$ $\left(\mathrm{mol} \mathrm{H}_{2}\right)^{-1}, 2021$.

2 W. R. Browne, Electrochemistry, Oxford University Press, New York, NY, 2018.

3 E. Wiberg and N. Wiberg, Lehrbuch der anorganischen Chemie, Walter de Gruyter, Berlin, 1995.

4 C.-H. Dustmann and A. Bito, in Encyclopedia of electrochemical power sources. Vol. 4, ed. J. Garche, Elsevier, Acad. Press, Amsterdam, 2009, pp. 324-333.

5 J. L. Sudworth and A. R. Tilley, The sodium sulfur battery, Chapman and Hall, London, 1985.

6 J. W. Braithwaite and W. L. Auxer, SODIUM BETA BATTERIES, Sandia National Laboratories Report SAND93-0047J.

7 A. E. Sarasua, M. G. Molina, D. E. Pontoriero and P. E. Mercado, in 2010 IEEE/PES Transmission and Distribution Conference and Exposition: Latin America (T\&D-LA), IEEE, Sao Paulo, Brazil, 2010, pp. 555-560.

8 B. L. Ellis and L. F. Nazar, Curr. Opin. Solid State Mater. Sci., 2012, 16, 168-177.

9 A. Bito, IEEE Power Eng. Soc. Gen. Meet. 2005, 2005, 1232-1235 Vol. 2.

10 M. Kamibayashi and K. Furuta, High Charge And Discharge Cycle Durability Of The Sodium Sulfur (NAS) Battery, Sandia National Laboratories, 2002.

11 C.-H. Dustmann, J. Power Sources, 2004, 127, 85-92.

12 G. Li, X. Lu, J. Y. Kim, K. D. Meinhardt, H. J. Chang, N. L. Canfield and V. L. Sprenkle, Nat. Commun., 2016, 7, 10683.

13 J. Ortega y Gasset and H. L. Nostrand, Mission of the university, Transaction Publishers, New Brunswick (U.S.A.), 1992. 